\title{
Pemanfaatan Air Buangan Ac Untuk Tanaman Hias Berbasis Internet Of Things
}

\author{
Eky Arjayanto Nurhasana ${ }^{1)}$, Hermansyah $^{2)}$, Lely Aylia $^{3)}$, Kasim $^{4)}$ \\ 1,2,3,4 Jurusan Teknik Elektro Politeknik negeri Ujung Pandang \\ Email: purna.hermansyah²)@gmail.comlelyaylia.la ${ }^{3) @ g m a i l . c o m ~}$ \\ kasim@poliupg.ac.id ${ }^{4}$
}

\begin{abstract}
Abstrak
Dalam kaitannya untuk memanfaatakan air buangan AC dan penggunaan air dalam menyiram tanaman khususnya tanaman hias serta memberikan kesadaran untuk upaya penghematan air. Dengan menggunakan aplikasi rangkaian elektronika berbasis Internet of Things (IoT) yang merupakan salah satu program yang dikembangkan untuk mempermudah proses penyiraman dan pemupukan pada tanaman secara otomatis. Salah satu cara yang dapat dilakukan adalah dengan dengan menggunakan perangkat-perangkat IoT sebagai alat kontrol. Produk ini diharapkan dapat menjadi produk yang bisa dijual ke pasaran dengan harga yang terjangkau. dan memiliki fungsi yang ramah lingkungan dan dapat digunakan oleh seluruh kalangan ke depannya. Kegiatan pembuatan produk ini dimulai dengan tahap awal yakni observasi ruangan yang menggunakan AC dan membuat model desain, setelah mendapatkan ruangan yang tepat, selanjutnya adalah mempersiapkan perangkat yang akan digunakan untuk membuat produk baik alat elektronik maupun non elektronik dan terakhir mempersiapkan tools yang akan digunakan untuk instalasi dan konfigurasi alat. Setelah produk selesai, selanjutnya adalah pengujian produk. Tahap akhir mencakup cek fungsional untuk menentukan apakah alat berfungsi dengan baik berdasarkan desain sistem yang sudah dirancang.
\end{abstract}

Kata Kunci : Air Buangan AC, Internet of Things.

\section{PENDAHULUAN}

Air Conditioner (AC) merupakan suatu modifikasi pengembangan teknologi mesin pendingin yang dimanfaatkan untuk berbagai tujuan terutama yang bertempat tinggal di wilayah subtropis (Samik, Setiarso dan Sanjaya, 2017). AC menghasilkan limbah berupa air buangan. Air buangan AC tersebut berasal dari udara panas yang diserap dari satu tempat kemudian dikeluarkan ke tempat lain melalui evaporasi (penguapan) dan kondensasi (Sarbu, 2014). Kondensasi (pengembunan) udara yang mengandung uap air menghasilkan air dalam bentuk cair. (Hari P, Anakorin dan Retno, 2016) menemukan bahwa kondensasi AC biasanya hanya dibuang begitu saja, padahal air yang keluar dari AC merupakan air murni hasil kondensasi dari udara lingkungan, yang kandungan pengotornya hanya berasal dari udara saja dan dapat dimanfaatkan. Oleh karena itu salah satu pemanfaatan kondensasi air AC dapat digunakan untuk menyiraman tanaman hias.

Tanaman hias mencakupi semua tumbuhan, yang sengaja ditaman sebagai komponen taman, kebun rumah, tanaman hias ataupun sebagai komponen karangan bunga. Perawatan tanaman hias harus secara intensif dan berkala agar tanaman selalu terlihat sehat dan indah sepaanjang waktu. Penyiraman, air merupakan unsur penting untuk proses metabolik pada tanaman. Pemupukan, tanaman memerlukan berbagai unsur hara (nutrisi) agar dapat tumbuh dan berkembang (Syahriefal, Harsani dan Mulyana, 2014). Salah satu metode penyiraman 
tanaman dengan menggunakan prinsip Drip Irrigation atau irigasi tetes.

Prinsip irigasi tetes atau yang sering disebut dengan Trickle Irrigation atau Drip Irrigation adalah irigasi yang menggunakan jaringan aliran dengan memanfaatkan gaya gravitasi. Jaringan irigasi tetes terdiri dari pipa utama, pipa sub utama dan pipa lateral. Pada ujung pipa lateral terdapat pemancar (emitter) yang digunakan untuk mendistribusikan air secara merata pada tanaman sesuai kebutuhan. Sistem irigasi tetes mempunyai cara pengontrolan yang baik sejak air dialirkan sampai diserap tanaman. Di samping itu sistem irigasi tetes mengurangi proses penguapan (evaporasi), di mana nutrisi dapat langsung diberikan ke tanaman melalui irigasi. (Fitriana, Arianti dan Semipermas, 2015). Penggunaan air pada irigasi tetes dapat menggunakan air buangan kondensasi AC.

Solusi yang ditawarkan yaitu model irigasi tetes untuk buangan kondensasi air AC yang dapat dimanfaatkan secara penuh untuk menyiram tanaman. Dengan menggunakan aplikasi rangkaian elektronika berbasis Internet of Things (IoT) yang merupakan salah satu program yang dikembangkan untuk mempermudah proses penyiraman dan pemupukan pada tanaman secara otomatis. Salah satu cara yang dapat dilakukan adalah dengan dengan menggunakan perangkat-perangkat IoT sebagai alat kontrol. Sehingga alat ini bisa diprogram untuk melakukan penyiraman pada tataman secara otomatis berdasarkan perintah yang telah ditentukan.

\section{Kajian Literatur}

\subsection{Air Conditioning (AC)}

Laju alir dari kondensat AC semakin besar dengan penurunan suhu operasi $\mathrm{AC}$, hal ini dikarenakan bahwa bila semakin kecil suhu yang kita inginkan maka semakin banyak udara yang diserap oleh $\mathrm{AC}$ pada ruangan tersebut yang akan dikonversi pada bagian evaporator AC menjadi refrigerant yang akan dialirkan ke dalam kondensor sehingga kondensat yang dihasilkan akan menjadi lebih banyak.

\subsection{Tanaman Hias}

Tanaman hias merupakan salah satu komoditas potensial yang dapat dikembangkan baik dalam skala kecil maupun besar terbukti dari semakin tingginya minat masyarakat terhadap agribisnis berbagai tanaman hias. Hal ini mendorong meningkatnya jumlah pelaku usaha tanaman hias, produk tanaman hias, luas areal dan daerah pengembangan baru tanaman hias (Dingu, 2017).

\subsection{Irigasi Tetes}

Prinsip irigasi tetes atau yang sering disebut dengan Trickle Irrigation atau Drip Irrigation adalah irigasi yang menggunakan jaringan aliran dengan memanfaatkan gaya gravitasi. Jaringan irigasi tetes terdiri dari pipa utama, pipa sub utama dan pipa lateral. Pada ujung pipa lateral terdapat pemancar (emitter) yang digunakan untuk mendistribusikan air secara merata pada tanaman sesuai kebutuhan. Sistem irigasi tetes mengurangi proses penguapan (evaporasi), di mana nutrisi dapat langsung diberikan ke tanaman melalui irigasi. (Fitriana, Arianti and Semipermas, 2015).

\subsection{Internet of Things}

Internet of Things merupakan segala aktifitas yang pelakunya saling berinteraksi dan dilakukan dengan memanfaatkan internet. Dengan menerapkan sebuah konsep komputasi yang menggambarkan masa depan dimana setiap obyek fisik dapat terhubung dengan internet dan dapat mengidentifikasi dengan sendirinya antar perangkat yang lain (Sulistyanto dkk., 2015).

\subsection{Mikrokontroler}

Mikrokontroler adalah sebuah sistem komputer fungsional dalam sebuah chip. Di dalamnya terkandung sebuah inti prosesor, memori (sejumlah kecil Random Access Memory, memori program, atau keduanya), dan perlengkapan input output. Dengan kata lain, mikrokontroler adalah suatu alat elektronika digital yang mempunyai masukan dan keluaran serta kendali dengan program yang bisa ditulis dan dihapus dengan cara khusus, cara kerja mikrokontroler sebenarnya membaca dan menulis data (Ginting, 2012).

\subsection{Sensor}

Sensor adalah suatu peralatan yang berfungsi untuk mendeteksi gejalagejala atau sinyal-sinyal yang berasal dari perubahan suatu energi seperti energi listrik, energi fisika, energi 
kimia, energi biologi, energi mekanik dan sebagainya (Adrinta dkk., 2017). Sensor yang digunakan antara lain Soil Moisture Sensor, Water Flow Sensor, Solenoid Valve dan Real Time Clock (RTC).

\section{Metode Penelitian}

Tahapan proses untuk melaksanakan program ini diawali dengan proses studi pendahuluan hingga tahap akhir yaitu implementasi. Gambar 1 merupakan gambaran tahapan proses program.

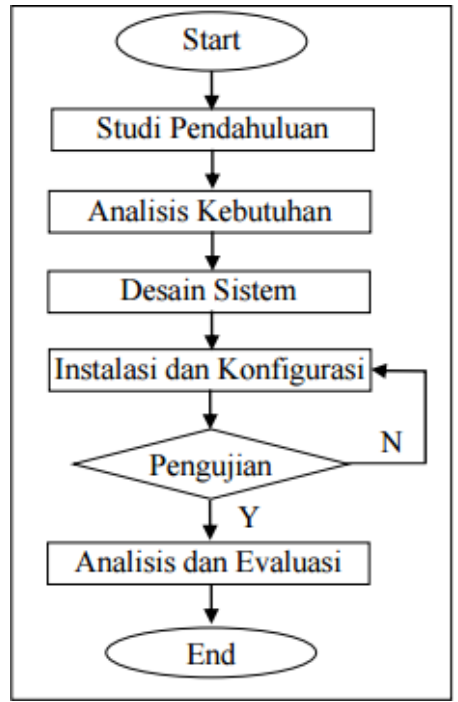

Gambar 1. Tahap Proses

Berikut ini merupakan uraian dari setiap tahapan proses penelitian yang akan dilakukan:

\subsection{Studi Pendahuluan}

Studi pendahuluan dilakukan dengan berbagai teknik seperti pengumpulan data yang akurat, relevan, dan reliable guna memperlancar proses perancangan sistem. Pengumpulan data dilakukan dengan cara studi literatur untuk mengumpulkan dan memperoleh data yang tepat dengan cara mempelajari, membaca, dan mencatat literatur dari beberapa buku, jurnal maupun dari internet baik berupa teori, laporan atau penemuan sebelumnya yang berkaitan dengan permasalahan serta mengkaji literatur ilmiah yang berkaitan dengan tujuan kegiatan.

\subsection{Analisis Kebutuhan}

Analisis dilakukan guna memperoleh gambaran tentang model rancangan perangkat yang nantinya akan digunakan. Rancangan dengan menggunakan 1 buah $\mathrm{AC}$ dan menggunakan penampungan sementara untuk menampung semua air buangan dari AC.

\subsection{Desain Sistem}

Desain sistem merupakan tahap pendefinisian dari analisis kebutuhan yang menggambarkan desain sistem yang akan dirancang. Gambar 2 merupakan gambaran desain sistem yang akan dirancang.

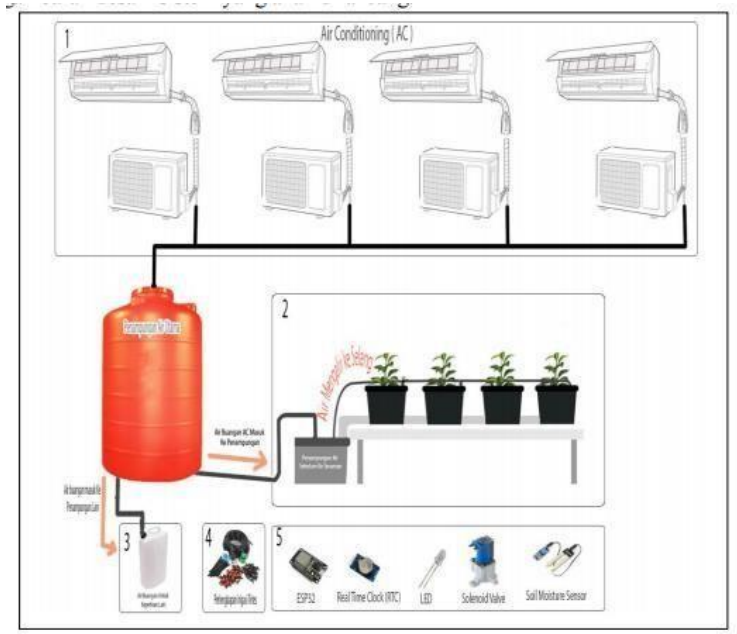

Gambar 2. Desain Sistem

1) Air buangan dari Air Conditioning (AC) yang masuk ke penampungan utama.

2) Air AC masuk kepe tempat penampungan sebelum di teruskan ke tanaman.

3) Air AC digunakan untuk keperluan lain seperti untuk air radiator mobil.

4) Perlengkapan irigasi tetes.

5) Perlengkapan mikrokontroler.

\subsection{Instalasi dan Konfigurasi}

Pada tahap ini dilakukan implementasi sistem mulai dari pengadaan perangkat yang dibutuhkan sistem, konfigurasi, pengkodean script, compile dan upload hingga pengujian sistem sesuai dengan kebutuhan. Pada Gambar 3 merupakan tahap instalasi dan konfigurasi. 


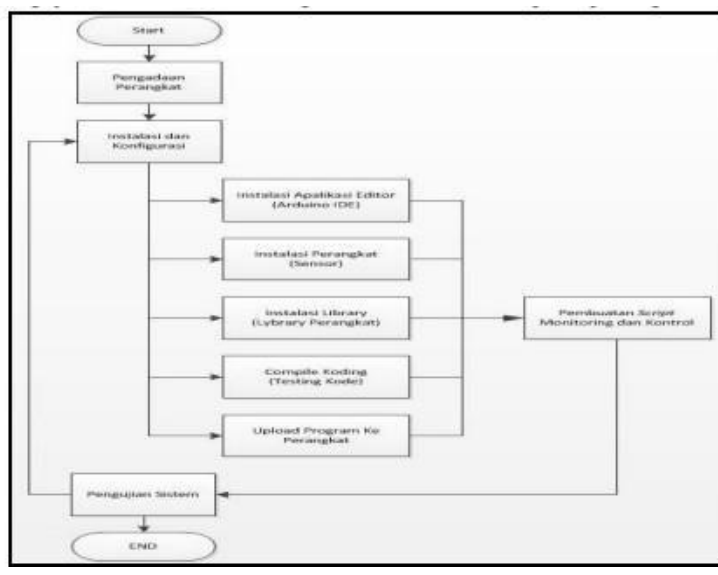

Gambar 3.Tahap Instalasi

\subsection{Pengujian}

Pengujian merupakan bagian yang penting dilakukan karena dapat menjadi tolak ukur bagaimana kehandalan sistem dapat bekerja dan kekurangan sistem yang perlu diperbaiki lebih lanjut. Apabila terdapat masalah/error pada saat pengujian maka akan kembali ke tahap instalasi. Beberapa pengujian yang akan dilakukan yaitu :

1) Pengujian sensor Pengujian dilakukan untuk memastikan sensor yang digunakan semua berfungsi dan kalibrasi nilai pengukuran sesuai nilai standar atau tidak.

2) Pengujian penyiraman. Pengujian dilakukan untuk mengetahui apakah penyiraman berfungsi sesuai dengan data kelembaban tanah atau tidak.

Persentasi kelembaban $=$

Nilai (1024 - nilai kelembaban analog) x 100\%

1024

\subsection{Evaluasi}

Pada tahapan ini dilakukan tahap analisis dan evaluasi terhadap hasil pengukuran dan pengujian tiap parameter dengan melihat referensi, selanjutnya dijadikan bahan dokumen menjadi laporan akhir. Masalah yang ditemukan dalam proses pembuatan turut dijadikan sebagai data hasil untuk mengembangkan produk lebih lanjut.

\section{Hasil dan Pembahasan}

Pada penelitian ini alat penyiraman tanaman dengan memanfaatkan air buangan Ac menggunakan alat mikrokontroler ESP826. Sensor kelembaban tanah (Soil Moisture Sensor) akan mendeteksi tingkat kekeringan tanah, Water Flow Sensor akan menghitung volume air yang digunakan. Jika tanah dalam kondisi kering maka mikrokontroler akan memerintahkan Real Time Clock (RTC) untuk membuka dan mengalirkan air Selenoid Valve (keran air yang dapat dikontrol). Jika tanah sudah basah sesuai dengan yang dibutuhkan tanaman maka relay memeritahkan solenoid valve menutup dan air tidak akan mengalir.

\subsection{Implementasi}

1) Perakitan alat dan bahan :

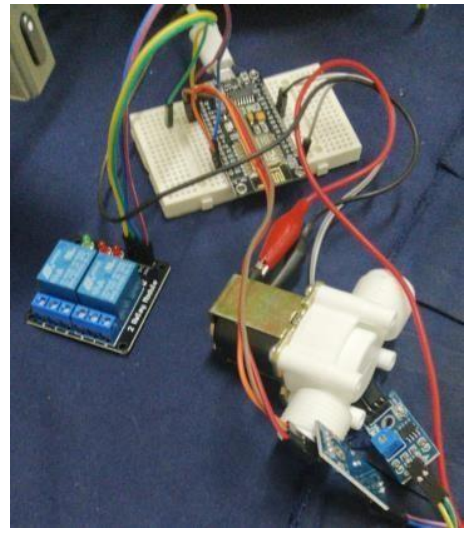

Gambar 4. Instalasi Alat

2) Pengerjaan Program :

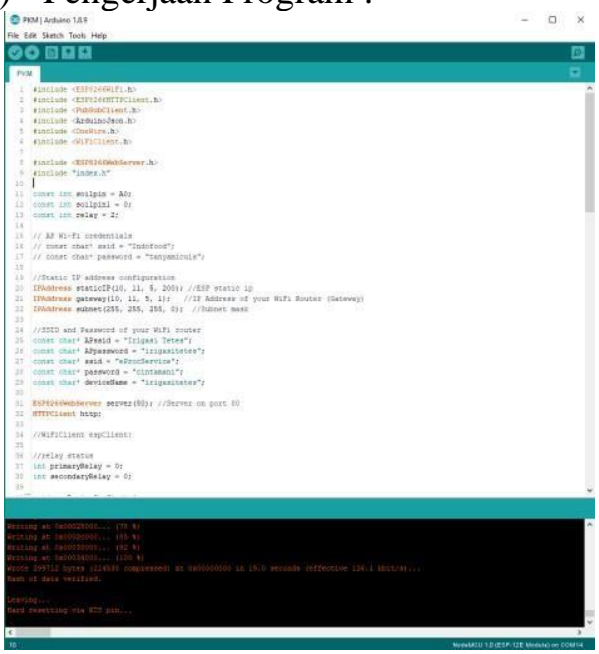

Gambar 5. Pengerjaan Program 


\subsection{Pengujian Perangkat Penyiraman}

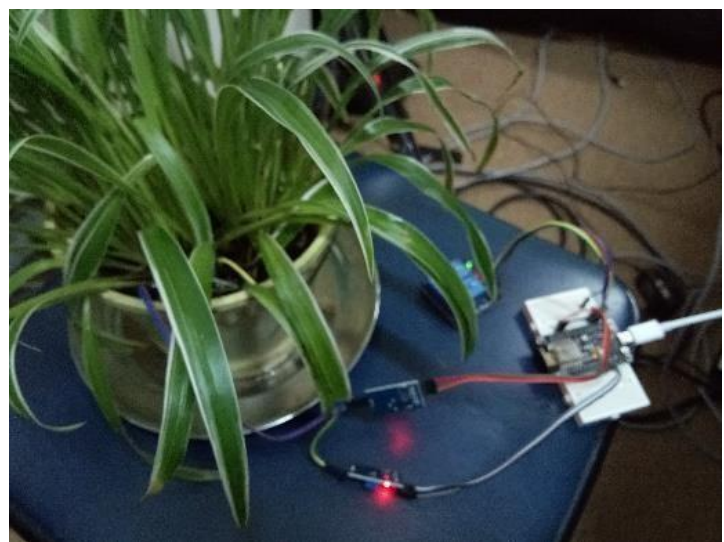

Gambar 6. Instalasi Alat dan Tanaman

Persentasi $>50 \%$ tanah dinyatakan basah, persentasi $25 \%$ - $49 \%$ tanah dinyatakan lembab dan persentasi $0 \%$ - $24 \%$ tanah dinyatakan kering.

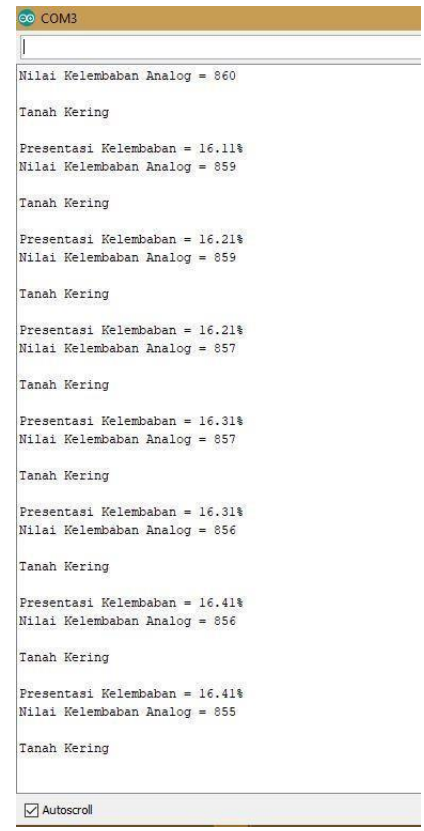

Gambar 7. Data Kelembaban Tanah Kering

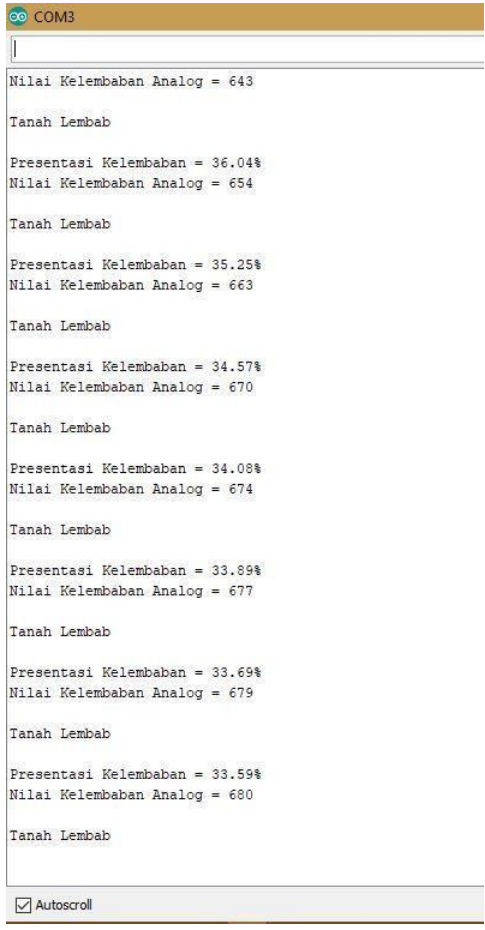

Gambar 8. Data Kelembaban Tanah Lembab

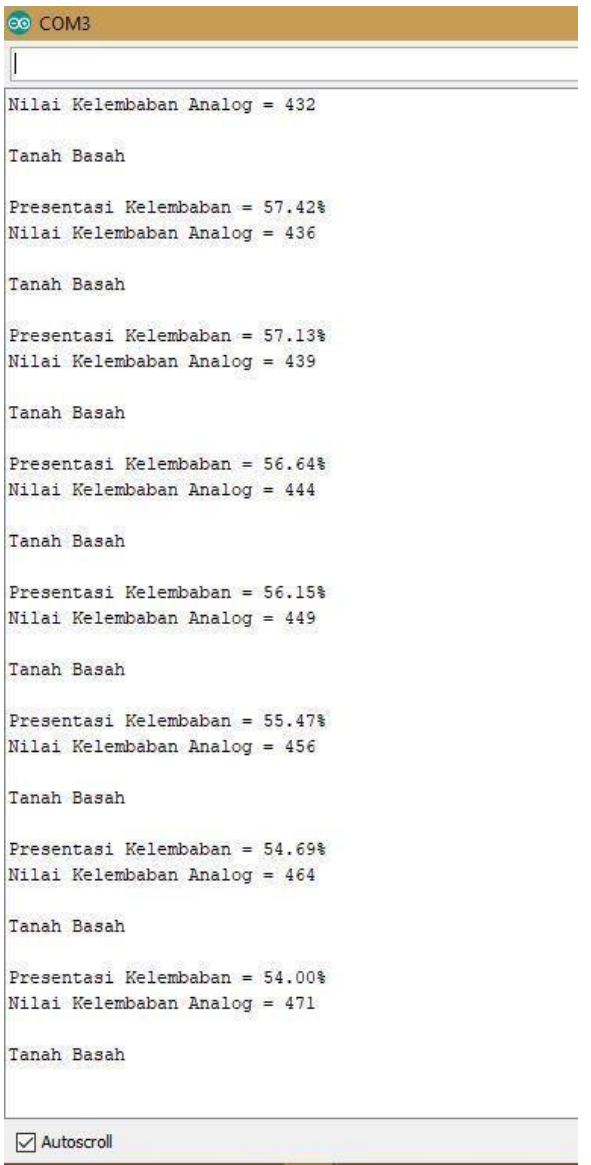

Gambar 9. Data Kelembaban Tanah Basah 


\section{Kesimpulan}

Air buangan AC dapat dimanfaatkan untuk menyiram tanaman. Kondensasi AC biasanya hanya dibuang begitu saja, padahal air yang keluar dari AC merupakan air murni hasil kondensasi dari udara lingkungan, yang kandungan pengotornya hanya berasal dari udara saja dan dapat dimanfaatkan. Oleh karena itu salah satu pemanfaatan kondensasi air AC dapat digunakan untuk menyiraman tanaman hias dengan metode. Pada penelitian ini berhasil dilakukan penyiraman otomatis berbasis Internet of Things dengan memanfaatkan air AC dengan batas nilai kelembaban basah $<50 \%$, lembab $25 \%-49 \%$ dan kering $0-24 \%$.

\section{Daftar Pustaka}

[1] Adrinta, M. A. et al. (2017) 'Sensor', Universitas Sumatera Utara, 1.

[2] Dingu, R. U. (2017) 'Pengaruh Pemberian Pupuk Urea dan $\mathrm{KCl}$ Pada Tanaman Krisan (Chrysanthemum morifolium)', Universitas Warmadewa, Bali, Indonesial, p. 300.

[3] Fitriana, N., Arianti, F. D. and Semipermas, M. N. (2015) 'Irigasi Tetes: Solusi Kekurangan Air pada Musim Kemarau', Balai Pengkajian Teknologi Pertanian Jawa Tengah, (40), pp. 273 277.

[4] Ginting, B. N. (2012) 'Penggerak Antena Modem USB Tiga Dimensi Berbasis
Mikrokomputer Menggunakan Arduino Uno', Departemen Fisika, Fakultas Matematika dan Ilmu Pengetahuan Alam, Universitas Sumatra Utara.

[5] Hari P, B., Anakorin, D. and Retno, T. M. (2016) 'Studi Pemanfaatan Kondensat Air Conditioning ( AC ) Menjadi Air Layak Minum', Prosiding Seminar Nasional Teknik Kimia 'Kejuangan', pp. 1-4.

[6] Samik, Setiarso, P. and Sanjaya, I. G. M. (2017) 'Pemanfaatan Air Buangan AC (Air Conditioner) Sebagai Pengganti Akuades', Department of Chemistry, Universitas Negeri Surabaya,Ketintang, Surabaya, 60243, Indonesia, (1), pp. 1-8.

[7] Sarbu, I. (2014). A review on substitution strategy of non-ecological refrigerants from vapour compressionbased refrigeration, airconditioning and heat pump systems. International Journal of Refrigeration, 46, 123141.

[8] Sulistyanto, M. P. T. et al. (2015) 'Implementasi IoT (Internet of Things) dalam pembelajaran di Universitas Kanjuruhan Malang', SMARTICS Journal, Universitas Kanjuruhan Malang, 1(1), pp. 20-23

[9] Syahriefal, M. A., Harsani, P. and Mulyana, I. (2014) 'Model Sistem Pemeliharaan Tanaman Otomatis Berbasis Mikrokontroller', Jurnal Online Mahasiswa. 